\title{
In Vitro Responses to Leishmania Antigens by Lymphocytes from Patients with Leishmaniasis or Chagas' Disease
}

\author{
Steven G. Reed," Edgar M. Carvalho, ${ }^{\ddagger}$ Cynthia H. Sherbert, ${ }^{\star}$ Diana Pedral Sampaio, ${ }^{\ddagger}$ Donna M. Russo, ${ }^{\star}$ Olivia Bacelar, ${ }^{\ddagger}$ \\ Deanna L. Pihl," Jeannine M. Scott, * Aldina Barral, ${ }^{\ddagger}$ Kenneth H. Grabstein," and Warren D. Johnson, Jr." \\ ${ }^{*}$ Seattle Biomedical Research Institute, Seattle, Washington 98109; ${ }^{\ddagger}$ Hospital Professor Edgard Santos, \\ Federal University of Bahia, 40.140 Bahia, Brazil, \$Immunex Corporation, Seattle, Washington \\ 98101; and "Cornell University Medical College, New York, New York 10021
}

\begin{abstract}
$T$ cell responses are correlated with recovery from and resistance to leishmaniasis. Antigens of Leishmania chagasi were evaluated by determining their ability to elicit in vitro proliferation and cytokine production in peripheral blood lymphocytes and in $\mathbf{T}$ cell lines and clones from patients with histories of leishmaniasis or Chagas' disease. Antigens tested were selected by their reactivity with patient antibodies. Several of the antigens induced proliferative responses in peripheral blood lymphocytes from patients recovered from visceral or cutaneous leishmaniasis or with chronic Chagas' disease. Two purified glycoproteins, 30 and $42 \mathrm{kD}$, were consistently among the most effective in eliciting high proliferative responses and IL-2 production. Lymphocytes from a recovered visceral leishmaniasis patient were used to produce $T$ cell lines against either the 30- or 42-kD antigen. Each of the lines responded to both of these antigens as well as to crude leishmania lysate. CD4 $+T$ cell clones specific for either or both of these antigens were also isolated from a visceral leishmaniasis patient. In contrast, rabbit antisera produced against these two antigens were not crossreactive. Both antigens were effective in inducing the production of IFN- $\gamma$ from $\mathrm{T}$ cell lines from both leishmaniasis and Chagas' disease patients. These studies demonstrate the potential for defining parasite antigens with broad immunostimulatory capabilities. (J. Clin. Invest. 1990. 85:690-696.) leishmania $\bullet$ antigens $\bullet T$ cells $\bullet$ leishmaniasis
\end{abstract}

\section{Introduction}

The leishmania are a complex of protozoan parasites that cause a spectrum of clinical diseases, including cutaneous, mucosal, and visceral leishmaniasis. They are obligate intracellular parasites of macrophages, which has important immunologic and therapeutic implications. $T$ cell responses are of fundamental importance in leishmaniasis. In visceral leishmaniasis recovery is strongly correlated with a delayed-type hypersensitivity response to leishmania antigens (1-3), as well as with proliferation of peripheral blood lymphocytes (4). $\mathrm{Pa}-$ tient's $T$ cells also produce IFN- $\gamma$ and IL- 2 after recovery from acute disease (5). This is of particular interest since IFN- $\gamma$ has

Address correspondence to Dr. Steven G. Reed, Seattle Biomedical Research Institute, 4 Nickerson St., Seattle, WA 98109.

Received for publication 27 February 1989 and in revised form 12 September 1989.

J. Clin. Invest.

(C) The American Society for Clinical Investigation, Inc.

0021-9738/90/03/0690/07 \$2.00

Volume 85, March 1990, 690-696 been shown to inhibit the in vitro proliferation of leishmania in macrophages (6). Based on these observations, it appears that evaluation of $\mathrm{T}$ cell responses to purified antigens is a logical way to identify molecules of leishmania with diagnostic and immunoprophylactic potential. In the present study we have identified and analyzed isolated antigens of Leishmania chagasi, the etiological agent of American visceral leishmaniasis. We have used these antigens to stimulate $T$ cells from patients recovered from disease caused by $L$. chagasi or by the related parasites, L. braziliensis, L. amazonensis, and Trypanosoma cruzi. The parameters used for antigen evaluation were lymphocyte proliferation, IL-2 production by patient's peripheral blood lymphocytes, IFN- $\gamma$ production by $\mathrm{T}$ cell lines, and characterization of $\mathrm{T}$ cell clones stimulated by selected antigens.

\section{Methods}

Parasite antigen preparation. A clone of $L$. chagasi (MHOM/BR/82/ BA-2, C1) was used in all studies (7). Promastigotes were grown to stationary phase $\left(2-3 \times 10^{7} / \mathrm{ml}\right)$ in RPMI 1640 (Gibco Laboratories, Grand Island, NY), supplemented with L-glutamine, Na pyruvate, MEM essential and nonessential amino acids (Gibco Laboratories), and 10\% SeruMax (Sigma Chemical Co., St. Louis, MO). Crude antigen was prepared by sonicating promastigotes in $10 \mathrm{mM}$ Tris, $\mathrm{pH} 7.5$, $2 \mathrm{mM}$ EDTA, $1.6 \mathrm{mM}$ PMSF (Sigma Chemical Co.), and $100 \mu \mathrm{g} / \mathrm{ml}$ leupeptin (Sigma Chemical Co.), followed by centrifugation $(5,000 \mathrm{~g}$, $20 \mathrm{~min}$ ). Protein content of the supernatant was determined by the Pierce assay (Pierce Chemical Co., Rockford, IL). Preparative SDSPAGE was performed by loading $3.2 \mathrm{mg}$ total parasite protein onto a $1.5-\mathrm{mm}$-thick $12 \%$ polyacrylamide gel in sample buffer $(50 \mathrm{mM}$ Tris$\mathrm{HCl}, 1 \%$ SDS, $10 \%$ glycerol, $2 \%$ 2-mercaptoethanol, $0.01 \%$ bromphenol blue) and running by standard procedure. A section of the gel was transferred to nitrocellulose for immunoblotting with patient serum for antigen band identification. Bands of interest were excised and gel slices were diced into 2-3-mm cubes and soaked overnight at $4^{\circ} \mathrm{C}$ in $2 \%$ SDS, $0.4 \mathrm{M} \mathrm{NH}_{4} \mathrm{HCO}_{3}$, and $0.1 \%$ dithiothreitol. The gel pieces and the soaking buffer were then placed into an electro-eluter (Bio-Rad Laboratories, Richmond, CA). Elution occurred for 6-7 h at $10 \mathrm{~mA}$ per tube in $0.05 \mathrm{M} \mathrm{NH}_{4} \mathrm{HCO}_{3}, 0.1 \%$ SDS. The eluted fractions were dialyzed against $0.01 \mathrm{M} \mathrm{NH}_{4} \mathrm{HCO}_{3}, 0.02 \%$ SDS for $24 \mathrm{~h}$, followed by dialysis against a minimum of 100 vol of PBS, pH 7.4, for 3-5 d with two buffer changes per $24 \mathrm{~h}$. All dialysis was done at $4^{\circ} \mathrm{C}$. Eluted samples were assayed for protein content (Pierce assay) and checked for purity on SDS-PAGE mini-gels with silver staining (Bio-Rad Laboratories). High molecular weight protein standards (Bethesda Research Laboratories, Bethesda, MD) were used.

Proteolysis treatments. Some of the eluted fractions were treated with cyanogen bromide ( $\mathrm{CnBr}$; Eastman Kodak Co., Rochester, NY), trypsin (Boehringer Mannheim Biochemicals, Indianapolis, IN), and endolys C (Wako Chemicals USA, Dallas, TX). Proteolysis reactions occurred under the following conditions: $\mathrm{CnBr} ; 2$ parts $\mathrm{CnBr}$ : 1 part protein (wt/wt), incubated in $70 \%$ formic acid, $30 \%$ water at room temperature for up to $16 \mathrm{~h}$. Trypsin; 25 parts protein dissolved in 50 
$\mathrm{mM} \mathrm{NaCl}, 1 \mathrm{mM} \mathrm{MgCl} 2,0.1 \mathrm{mM}$ EDTA $10 \mathrm{mM}$ Pipes buffer, pH 7.8; 1 part enzyme (wt/wt), incubated at room temperature for $16 \mathrm{~h}$. Endolys $\mathrm{C} ; \mathbf{4 0 0}$ parts protein dissolved in $50 \mathrm{mM}$ Tris, $\mathrm{pH}$ 8.0:1 part enzyme (wt/wt), incubated at $30^{\circ} \mathrm{C}$ for $16 \mathrm{~h}$.

Immunoblotting. The electrophoresed parasites or fractions were transferred to nitrocellulose and the sheets were blocked and reacted with sera as described (7). Biotinylated goat anti-human IgG, A, and M (Zymed Laboratories, So. San Francisco, CA) was applied in a dilution of 1:8,000 in PBS-T and incubated for $30 \mathrm{~min}$, followed by two washes in PBS-T and a final wash in PBS. Avidin-alkaline phosphatase (Zymed Laboratories) was then applied, diluted 1:1,500 in PBS, and incubated for $30 \mathrm{~min}$. After three washes substrate was added consisting of nitro blue tetrazolium ( $330 \mu \mathrm{g} / \mathrm{ml}$; Sigma Chemical Co.) and 5-bromo-4 chloro-3 indolyl phosphate $(165 \mu \mathrm{g} / \mathrm{ml}$; Sigma Chemical Co.) in $100 \mathrm{mM}$ Tris (pH 9.5), $100 \mathrm{mM} \mathrm{NaCl}$, and $5 \mathrm{mM} \mathrm{MgCl}_{2}$.

Lectin blotting. Nitrocellulose strips were prepared as above, except that blocking was performed in BSA (1\% in PBS, pH 7.0). After rinsing, the strips were incubated in the following biotinylated lectins (Sigma Chemical Co.): Lens culinaris (lentil lectin), Arachis hypogaea (peanut lectin), Phaseolus vulgaris (PHA), Canavalia ensiformis (Con A), and Triticum vulgaris (wheat germ) at 1:400 in PBS-T at room temperature for $30 \mathrm{~min}$. After this incubation the strips were washed and incubated in avidin alkaline phosphatase and developed as above.

Antiserum production. Rabbits (adult New Zealand White; R \& R Rabbitry, Stanwood, WA) were immunized with eluted protein purified to a single band on an SDS gel for the production of polyclonal antisera. The immunization procedure consisted of two subcutaneous injections of $100 \mu \mathrm{g}$ protein, together with $500 \mathrm{ng}$ recombinant human IL-1- $\beta$ in Freund's incomplete adjuvant, given $30 \mathrm{~d}$ apart. Intravenous injections of $40 \mu \mathrm{g}$ protein were given 30 and $60 \mathrm{~d}$ after the second subcutaneous injection, and sera were collected $6 \mathrm{~d}$ after the final injection.

Biosynthetic labeling and radioimmunoprecipitation. Promastigote lysate was prepared as above, except that the parasites were first incubated $\left(4 \times 10^{7} / \mathrm{ml}\right.$ in medium containing $20 \mu \mathrm{Ci} / \mathrm{ml}\left[{ }^{35}\right.$ S]methionine (New England Nuclear, Boston, MA) for $14 \mathrm{~h}$ with shaking. $100 \mu \mathrm{l}$ of a $50 \%$ suspension of protein A-Sepharose beads (Zymed) were equilibrated in $50 \mathrm{mM} \mathrm{NaBO}$, pH 8.2, then combined with $25 \mu$ l rabbit serum and mixed for $30 \mathrm{~min}$ at room temperature. The beads were pelleted and suspended in cross-linking buffer $(200 \mathrm{mM}$ triethanolamine, $\mathrm{pH} 8.2$, with $6.1 \mathrm{mg} / \mathrm{ml}$ dimethyl pimelimidate $\cdot 2 \mathrm{HCl}$ (Pierce Chemical Co.), and mixed for $1 \mathrm{~h}$ at room temperature. The beads were then washed twice with cross-linking buffer and blocked with 100

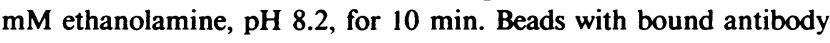
were equilibrated in PBS, pH 7.2, for use and storage.

For immunoprecipitation, $20 \mu \mathrm{l}$ of a $50 \%$ suspension of the conjugated beads was mixed with $50 \mu \mathrm{l}$ parasite lysate at $4^{\circ} \mathrm{C}$ for $2 \mathrm{~h}$. The beads were washed twice with PBS ( $\mathrm{pH}$ 7.2) containing $0.02 \% \mathrm{NaN}_{3}$, twice with mixed detergent buffer $(0.05 \%$ NP- $40,0.01 \%$ SDS, $0.3 \mathrm{M}$ $\mathrm{NaCl}, 10 \mathrm{mM}$ Tris $\mathrm{HCl}, \mathrm{pH} \mathrm{8.6)}$, and twice with PBS-azide. The beads were subjected to standard SDS-PAGE and autoradiography.

Leukocytes. PBL donors were as follows: (a) Visceral leishmaniasis; cells were taken from individuals living in an area endemic for visceral leishmaniasis with a history of acute disease due to $L$. chagasi infections 6 mo to $4 \mathrm{yr}$ previously, confirmed by isolation and identification of the parasite. ( $b$ ) Mucosal leishmaniasis; cells were from patients with active mucosal disease or with recently $(<1 \mathrm{yr})$ cured mucosal infections. (c) Cutaneous leishmaniasis; cells were collected from individuals with a recent history ( 6 mo to $2 \mathrm{yr}$ ) of simple cutaneous leishmaniasis, manifested as a single lesion. Patients in groups 2 and 3 were from areas endemic for $L$. braziliensis and had parasite-confirmed infections. (d) Chagas' disease; these patients had chronic Chagas' disease and were clinically, serologically, and parasitologically positive for $T$. cruzi infection. (e) Healthy controls: these cells were obtained from individuals living in areas endemic for leishmaniasis and Chagas' disease but without a history of these infections.

$T$ cell lines and clones. $T$ cell lines were generated from patients recovered from acute visceral leishmaniasis or cutaneous leishmaniasis and a patient with chronic T. cruzi infection. PBL were separated on lymphocyte separation medium (Organon Teknika Corp., Durham, NC) and frozen in liquid nitrogen in aliquots of $2 \times 10^{7}$ in $1 \mathrm{ml}$. T cell cultivation medium consisted of RPMI 1640 (Gibco Laboratories) supplemented with L-glutamine, Na-pyruvate, 2-mercaptoethanol, and $10 \%$ screened human $\mathrm{A}^{+}$or $\mathrm{AB}^{+}$serum (complete medium). $\mathrm{T}$ cell lines were also generated using purified antigens instead of crude lysate.

To generate clones, PBL were cultured for $5 \mathrm{~d}$ with crude leishmania (leishmaniasis patients) or $T$. cruzi (Chagas' patients) lysate $\left(10^{6}\right.$ cells per $\mathrm{ml}, 2 \mathrm{ml}$ per well in a 24-well tray, incubated $5 \mathrm{~d}$ with $5 \mu \mathrm{g}$ parasite protein $/ \mathrm{ml}$ ). $\mathrm{T}$ cell blasts, separated in lymphocyte separation medium, were cloned and subcloned by limiting dilution at 0.3 cells/ well in 96-well, round-bottom plates (No. 25805; Corning Glass Works, Corning, NY). Clonality was determined according to frequency of positives at limiting dilutions by established methods $(8,9)$. Clones were maintained by biweekly feedings with human recombinant IL-4 $(100 \mathrm{ng} / \mathrm{ml})$, and by stimulation every $10-14 \mathrm{~d}$ with irradiated (3,500 rad) autologous whole PBL and leishmania lysate (5 $\mu \mathrm{g} / \mathrm{ml})$ with human recombinant $\mathrm{IL}-2(10 \mathrm{ng} / \mathrm{ml})$.

Proliferative assays and cytokine production. 7-10 d after antigen stimulation, $10^{4}$ cloned $T$ cells were cultured with $10^{5}$ irradiated autologous feeder PBL in $200 \mu \mathrm{l}$ complete medium in triplicate wells of 96-well plates (No. 3595; Costar, Cambridge, MA) with or without $0.5-1 \mu \mathrm{g}$ antigen protein/well. After $3 \mathrm{~d}$ incubation the cells were pulsed overnight with $\left[{ }^{3} \mathrm{H}\right]$ thymidine $(0.5 \mu \mathrm{Ci} /$ well $)$. Stimulation index is counts per minute of culture with antigen/counts per minute of culture without antigen. For IFN- $\gamma$ and IL-2 production, supernatants were collected after 24-96 $\mathrm{h}$ incubation and assayed for IFN- $\gamma$ by the WISH cell bioassay (10), or for IL-2 by the CTLL bioassay (11).

\section{Results}

PBL proliferative responses to parasite lysate or to partially purified antigens. Major antigenic bands of the SDS-PAGEseparated $L$. chagasi were identified using a serum pool from patients recovered from visceral leishmaniasis (Fig. 1). Sera from normal individuals did not recognize leishmania antigens, as we have previously shown (7). In initial studies, bands of $M_{\mathrm{r}} 116,78,72,70,65,42,40,30$, and $16 \mathrm{kD}$ were chosen for use in in vitro proliferation assays. These bands were chosen based on their reactivity with sera from visceral leishmaniasis patients and with sera from Chagas' patients (Fig. 1). Several bands, for example the 42- and $30-\mathrm{kD}$ antigens, were recognized by Chagas' patient sera, as well as by leishmaniasis sera, while others, such as the $65-\mathrm{kD}$ antigen, were recognized by leishmaniasis but not Chagas' patient sera. Coomassie

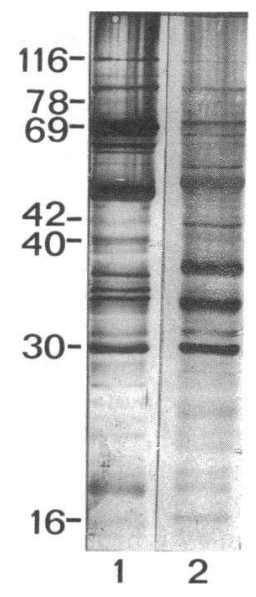

Figure 1. Immunoblot of whole $L$. chagasi lysate (10 $\mu \mathrm{g}$ protein/lane) separated by SDSPAGE and reacted with pooled sera from five individuals with cured visceral leishmaniasis diluted 1:300 (lane 1 ) or from five patients with chronic $T$. cruzi infection diluted 1:100 (lane 2). 
blue-stained bands corresponding to the desired antigenic regions were excised and eluted from the gel and dialyzed to remove SDS. The purity of the fractions was ascertained on polyacrylamide gels before use in cell stimulation assays. All bands retained their antigenicity, as indicated by their ability to bind antibody from patients with cured visceral leishmaniasis on immunoblots (not shown). All proliferative assays were performed with antigens purified to a single SDS-PAGE band (Fig. 2).

The results from testing normal or patient cells for their ability to proliferate in response to crude homogenate or to representative partially purified leishmania antigens are shown in Table I. Several of the antigens were effective in stimulating PBL from visceral, mucosal, and cutaneous leishmaniasis patients, while none of the antigens tested stimulated significant proliferation in cells from normal individuals. Antigens of 30 , 40,42 , and $70 \mathrm{kD}$ were effective ( $>10$-fold proliferation above background) in stimulating significant proliferative responses in PBL cultures from leishmaniasis patients (Table I). However, two bands, 30 and $42 \mathrm{kD}$, also elicited responses in cultures of PBL from Chagas' patients. These two bands were the only partially purified antigens tested that consistently elicited high responses from all three patient groups, and they were therefore chosen for further study. In subsequent analyses, other antigens were assayed for their ability to elicit proliferation in patient PBL, but none were consistently more effective than those represented in Table I.

Cytokine production by $P B L$ and $T$ cell lines after exposure to leishmania antigens. The production of IL-2 by patient PBL (Table II) was found to correlate directly with proliferation responses. In these experiments lysate of leishmania or $T$. cruzi were compared with selected antigen bands for their ability to induce IL-2 in patient PBL. Initial experiments with whole leishmania lysate showed that maximal IL-2 production occurred in cells from leishmaniasis patients $48 \mathrm{~h}$ after antigen stimulation as compared with 24,72 , and $96 \mathrm{~h}$ (not shown). Therefore, cultures were established as in proliferation assays, and supernatants were collected for IL-2 determination $48 \mathrm{~h}$ after adding antigen. In general, antigens of 70,42 , and $30 \mathrm{kD}$ compared favorably with whole leishmania lysate in stimulating IL-2 production from all three groups of leishmaniasis patients as well as in Chagas' disease patients. None of the antigens tested elicited IL-2 production in PBL from normal individuals.

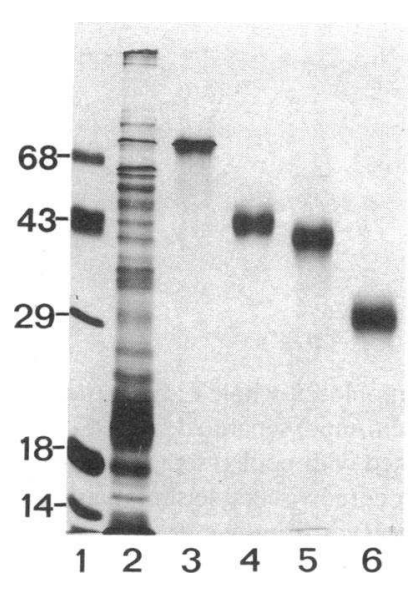

Figure 2. Analysis of excised bands from preparative SDSPAGE gels of $L$. chagasi lysate. $5 \mu \mathrm{g} L$. chagasi lysate (lane 2) or $1 \mu \mathrm{g}$ protein of eluted bands of $M_{\mathrm{r}} 69,42,40$, and $30 \mathrm{kD}$ (lanes 3-6) were analyzed on SDS-PAGE with silver strain. Lane 1 is high molecular weight standards.
T cell lines generated from patients with cured visceral or cutaneous leishmaniasis or with chronic Chagas' disease were tested for their ability to produce IFN- $\gamma$ in response to the 30and $42-\mathrm{kD}$ antigens. The results are shown in Table III. Cell lines from the two groups of leishmaniasis patients (visceral and cutaneous) produced significant levels of IFN- $\gamma$ in response to crude $L$. chagasi lysate, as we have previously reported for patient PBL (5). The production of IFN- $\gamma$ was maximum at $72 \mathrm{~h}$ (data not shown). In addition, both the 30and $42-\mathrm{kD}$ antigens elicited significant IFN- $\gamma$ production by $\mathrm{T}$ cell lines from both patient groups. Of particular interest was the ability of these antigens, as well as crude lysate, to elicit IFN- $\gamma$ production in $\mathrm{T}$ cell lines from Chagas' patients.

$\mathrm{T}$ cell lines were also generated using purified 30 - and 42-kD antigens by incubating PBL from a patient recovered from visceral leishmaniasis with gel-eluted protein. Lines were selected and restimulated using only the $30-$ or $42-\mathrm{kD}$ antigens and tested after $30 \mathrm{~d}$ in culture for responsiveness to crude lysate or to partially purified antigens. The results are shown in Table IV. Both of the T cell lines responded to crude leishmania lysate. In addition, the $\mathrm{T}$ cell line generated against the $30-\mathrm{kD}$ antigen responded to both the $30-$ and $42-\mathrm{kD}$ antigens. The same was true for the line generated against the $42-\mathrm{kD}$ antigen. This proliferation could not be explained by the survival of nonselected $T$ cells from the PBL; cultures of the same PBL without added antigen (30- or $42-\mathrm{kD}$ proteins) did not survive past day 10 of culture. These results suggest that $T$ cell epitopes may be shared by the 30 - and $42-\mathrm{kD}$ antigens.

To further characterize $T$ cells that responded to the 30 and 42-kD antigens, $T$ cell clones that were specific for these antigens were identified. $148 \mathrm{~T}$ cell clones were generated from a patient recovered from acute visceral leishmaniasis. Several of these clones that responded to crude antigen with proliferation $>30$-fold above background were also tested for proliferative responses to the $42-$ and $30-\mathrm{kD}$ fractions. Of 39 clones tested for proliferation to the $30-\mathrm{kD}$ antigen, 13 responded with a stimulation index of 10 -fold or higher (Table V). By the same criterion, 11 of 22 clones tested responded to the $42-\mathrm{kD}$ $L$. chagasi antigen. The majority of the clones responded to both antigens, but two responded to the 30 - and not the $42-\mathrm{kD}$ antigen, while one responded to the $42-$ and not the $30-\mathrm{kD}$ antigen. All of these clones were CD4+.

Partial characterization of the 42-and $30-k D$ fractions. Purity of the eluted fractions was obtained to the level of a single band on an SDS-PAGE gel (Fig. 2). The antigens were treated with different proteolytic agents, including $\mathrm{CnBr}$, trypsin, and endolys $\mathrm{C}$. Both antigens were digested by each of these treatments (Figs. 3 and 4), demonstrating their protein composition. In addition, each of the fractions bound all of the lectins used, as determined by incubation with biotinylated lectin followed by avidin-conjugated phosphatase. Binding of lentil lectin is illustrated in Fig. 5. These results indicated that the 42and 30-kD fractions appeared to be glycosylated.

Rabbit antisera raised against these two proteins demonstrated that they have unique antigen determinants. Sera from rabbits immunized with either antigen were immunoblotted on or used to immunoprecipitate leishmania lysates (Fig. 6, $a$ and $b$ ). Each of the sera bound to the respective antigens, and neither bound to both antigens. This was true whether the sera were reacted with denatured (Fig. $6 a$ ) or nondenatured (Fig. 6 b) leishmania lysate, illustrating that the $30-\mathrm{kD}$ antigen is not likely to be a breakdown product of the $42-\mathrm{kD}$ antigen. Fur- 
Table I. Proliferation of PBL from Patients with Past or Active Leishmaniasis or Chagas' Disease in Response to Antigens of L. chagasi

\begin{tabular}{|c|c|c|c|c|c|}
\hline \multirow[b]{3}{*}{$\begin{array}{c}\text { Antigen } \\
\text { (1 } \mu \mathrm{g} \text { protein/well) }\end{array}$} & \multicolumn{5}{|c|}{$\left[{ }^{3} \mathrm{H}\right]$ Thymidine uptake } \\
\hline & \multirow[b]{2}{*}{$\begin{array}{l}\text { Normal } \\
(n=10)\end{array}$} & \multicolumn{3}{|c|}{ Leishmaniasis } & \multirow[b]{2}{*}{$\begin{array}{c}\text { Chagas' disease } \\
\quad(n=8)\end{array}$} \\
\hline & & $\begin{array}{l}\text { Visceral } \\
(n=8)\end{array}$ & $\begin{array}{l}\text { Mucosal } \\
(n=3)\end{array}$ & $\begin{array}{l}\text { Cutaneous } \\
(n=4)\end{array}$ & \\
\hline$M_{r}$ & \multicolumn{5}{|c|}{ mean cpm $\times 10^{-3} \pm S D$} \\
\hline 116 & $0.3(0.2)$ & $1.7(1.4)$ & $4.8(3.2)$ & $0.9(1.1)$ & $2.9(2.0)$ \\
\hline 78 & $0.3(0.1)$ & $4.2(0.9)$ & $3.9(2.0)$ & $7.1(6.5)$ & $3.1(2.1)$ \\
\hline 70 & $0.6(0.2)$ & $4.1(2.4)$ & $18.1(9.5)^{*}$ & $12.8(4.2)$ & $6.5(2.9)$ \\
\hline 65 & $0.2(0.2)$ & $7.9(4.1)$ & $20.2(8.3)^{*}$ & $28.0(5.5)$ & $7.7(5.2)$ \\
\hline 42 & $0.3(0.1)$ & $13.5(3.6)^{*}$ & $37.6(12.4)^{*}$ & $31.1(8.0)$ & $18.2(6.4)^{*}$ \\
\hline 40 & $0.4(0.2)$ & $6.5(3.8)$ & $14.2(10.1)$ & $15.2(6.9)$ & $9.1(6.9)$ \\
\hline 30 & $0.4(0.3)$ & $12.7(4.8)^{*}$ & $45.8(12.5)^{*}$ & $46.1(10.0)$ & $21.5(6.3)^{*}$ \\
\hline 16 & $0.4(0.5)$ & $0.9(1.2)$ & $9.6(3.5)^{*}$ & $7.7(3.2)$ & $5.5(4.0)$ \\
\hline None (medium only) & $0.2(0.3)$ & $0.5(0.7)$ & $1.2(1.6)$ & $1.4(2.1)$ & $3.1(1.1)$ \\
\hline Leishmania lysate & $0.4(0.3)$ & $19.2(6.4)^{*}$ & $72.1(12.8)^{*}$ & $58.5(9.3)$ & $16.7(5.1)^{*}$ \\
\hline$T$. cruzi lysate & $0.2(0.3)$ & ND & ND & ND & $51.8(7.9)^{*}$ \\
\hline
\end{tabular}

$10^{5} \mathrm{PBL}$ were incubated for $5 \mathrm{~d}$ in the presence of antigen after a 12 -h pulse with $\left[{ }^{3} \mathrm{H}\right]$ thymidine. ${ }^{*}$ Significant $(P<0.05)$ proliferation above background (medium only wells).

ther, these data suggest the presence of unique antigenic determinants on glycoprotein (gp) 42 and gp 30 . The rabbit antiserum raised against gp 30 also precipitated a band of $\sim 55-60$ $\mathrm{kD}$. We are in the process of characterizing this molecule(s).

\section{Discussion}

PBL proliferative response to leishmania antigens has been used as a prognostic indicator for recovery from leishmaniasis. Proliferation of PBL in response to leishmania antigen is negative in patients with acute visceral leishmaniasis but occurs after successful therapy (4). In addition to proliferative responses, we have shown a correlation between the ability of patient PBL to produce IL-2 and IFN- $\gamma$ in response to leishmania antigens after recovery from acute infection (5). We have therefore chosen proliferation and cytokine production to evaluate human lymphocyte responses to selected leishmania antigens.

The approach used in this study to identify antigens of leishmania that may be important in stimulating leishmaniaspecific $T$ cell activity was to elute them from gels and use them in soluble form for lymphocyte assays. This can have advantages over the Western blot approach of antigen analysis, in which proteins transferred to nitrocellulose are used for in vitro lymphocyte assays. The use of antigens transferred to nitrocellulose makes it difficult to ensure either quantitatively or qualitatively that the same antigenic stimulus is consistently applied to each well. In contrast, when eluted soluble protein is used, it is possible to standardize a single lot of antigen for repeated testing.

Several antigens of $L$. chagasi stimulated PBL proliferative responses in the homologous patient group (persons with previous acute visceral leishmaniasis due to $L$. chagasi). Some of the antigens also elicited consistently high responses in PBL

1. Abbreviations used in this paper: $\mathrm{gp}$, glycoprotein. from cutaneous or mucosal leishmaniasis and in PBL from Chagas' disease patients. Cross-reactivity between antigens of different Leishmania species and between antigens of leishmania and $T$. cruzi occurs serologically $(7,12)$, and also in the PBL proliferation assay (13). Little has been done thus far to characterize the molecules that the parasites in these groups may have in common. Of the several proteins and glycoproteins shared by the leishmania that cause human disease, a 63-65-kD surface antigen appears to be highly conserved among these species and subspecies as judged by serological cross-reactivity $(7,14,15)$, and by DNA sequence analysis (our unpublished data). This antigen from $L$. chagasi appeared at $63-65 \mathrm{kD}$. This antigen is not recognized serologically by individuals with $T$. cruzi infections (7). However, it is interesting to note that this antigen was among the most effective in stimulating $T$ cells from both leishmaniasis and Chagas' patients. In

Table II. Production of IL-2 by PBL from Patients with Leishmaniasis or Chagas' Disease in Response to Antigens of L. chagasi

\begin{tabular}{|c|c|c|c|c|c|}
\hline \multirow[b]{3}{*}{ Antigen } & \multicolumn{5}{|c|}{ Units IL-2 produced* } \\
\hline & \multirow[b]{2}{*}{ Normal } & \multicolumn{3}{|c|}{ Leishmaniasis patients } & \multirow{2}{*}{$\begin{array}{l}\text { Chagas' } \\
\text { disease } \\
\text { patients }\end{array}$} \\
\hline & & Visceral & Mucosal & Cutaneous & \\
\hline \multicolumn{6}{|l|}{ L. chagasi } \\
\hline lysate & 0 & $29 \pm 5$ & $24 \pm 11$ & $32 \pm 0$ & $23 \pm 12$ \\
\hline T. cruzi lysate & 0 & ND & ND & ND & $48 \pm 23$ \\
\hline 116 & 0 & 0 & 0 & 0 & 0 \\
\hline 65 & 0 & $27 \pm 5$ & $18 \pm 22$ & $16 \pm 0$ & $8 \pm 4$ \\
\hline 42 & 0 & $27 \pm 5$ & $35 \pm 12$ & $27 \pm 5$ & $24 \pm 8$ \\
\hline 30 & 0 & $37 \pm 9$ & $36 \pm 26$ & $29 \pm 17$ & $31 \pm 18$ \\
\hline
\end{tabular}

* Units of IL-2 were determined in cultures identical to those in Table I $48 \mathrm{~h}$ after antigen stimulation. 
Table III. In Vitro IFN- $\gamma$ Production by T Cells Stimulated with L. chagasi 30- and 42-kD Antigens

\begin{tabular}{|c|c|c|c|c|c|}
\hline \multirow[b]{2}{*}{ Patient group* } & \multicolumn{5}{|c|}{ IFN- $\gamma^{\ddagger}$} \\
\hline & Medium & $\begin{array}{l}\text { L. chagasi } \\
\text { lysate }\end{array}$ & Gp 30 & Gp 42 & $\begin{array}{c}T . \text { cruzi } \\
\text { lysate }\end{array}$ \\
\hline
\end{tabular}

Cured visceral

$\begin{array}{llllll}\text { leishmaniasis }^{\S} & 0 & 32 \pm 0 & 21 \pm 4 & 21 \pm 9 & \text { ND } \\ \text { Cutaneous leishmaniasis }^{\S} & 0 & 36 \pm 8 & 16 \pm 0 & 32 \pm 0 & \text { ND } \\ \text { Chagas' disease }^{\ddagger} & 0 & 16 \pm 0 & 16 \pm 0 & 16 \pm 0 & 8 \pm 0\end{array}$

* No IFN- $\gamma$ was observed by cells from normal individuals stimulated with any of the antigens.

${ }^{\ddagger}$ IFN production was determined in unconcentrated culture supernatants from $5 \times 10^{4} \mathrm{~T}$ cells and $10^{5}$ irradiated autologous feeder cells cultured from $1 \mu \mathrm{g}$ antigen protein for $72 \mathrm{~h}$.

this regard, purified gp 63 from $L$. major was suggested to have some effectiveness in the induction of protective $T$ cell responses in mice (16).

Serological cross-reactivity was useful in selecting leishmania antigens for partial purification. Both gp 42 and gp 30 were identified initially on the basis of their reactivity with sera from patients with different forms of leishmaniasis and with sera from Chagas' disease patients. Although antigenic determinants recognized by $B$ cells may differ from those recognized by $T$ cells, as illustrated in studies on influenza virus (17, 18 ), selection of a protein for studies of $T$ cell responses was facilitated in this study by observations on antibody reactivity.

In the present study we have begun to characterize selected antigens of leishmania that are able to stimulate $T$ cells from individuals with past leishmania infections or with chronic $T$. cruzi infections. At least two antigens, gp 30 and gp 42, elicited consistently high proliferative responses in all three patient groups to levels roughly equivalent to those obtained using

Table IV. Proliferation of Selected T Cell Lines to the 30- and 42-kD Antigens

\begin{tabular}{|c|c|c|c|c|}
\hline \multirow[b]{3}{*}{ Antigen } & \multicolumn{4}{|c|}{$\left[{ }^{3} \mathrm{H}\right]$ Thymidine uptake } \\
\hline & \multicolumn{4}{|c|}{$\mathbf{T}$ cell lines } \\
\hline & gp 30 & $\begin{array}{l}\text { Stimulation } \\
\text { index }\end{array}$ & $\mathrm{gp} 42$ & $\begin{array}{l}\text { Stimulation } \\
\text { index }\end{array}$ \\
\hline & \multicolumn{4}{|c|}{ mean cpm $\times 10^{3} \pm S D$} \\
\hline \multicolumn{5}{|l|}{ L. chagasi lysate } \\
\hline \multicolumn{5}{|l|}{ Gp 42} \\
\hline (0.5 $\mu \mathrm{g}$ protein/well) & $7.2 \pm 2.6$ & 4.9 & $8.6 \pm 1.8$ & 5.2 \\
\hline \multicolumn{5}{|l|}{ Gp 30} \\
\hline (0.5 $\mu \mathrm{g}$ protein/well) & $9.2 \pm 2.8$ & 6.2 & $7.9 \pm 3.6$ & 4.8 \\
\hline None & $1.4 \pm 2.8$ & & $1.6 \pm 0.5$ & \\
\hline
\end{tabular}

* T cell lines were selected by stimulation of PBL from a patient recovered from visceral leishmaniasis with the 30 - or $42-\mathrm{kD}$ antigens eluted from gels (Fig. 1).
Table V. Proliferation of L. chagasi-specific T Cell Clones to $G p 30$ or $G p 42$

\begin{tabular}{lccc}
\hline \multicolumn{1}{c}{ Antigen } & $\begin{array}{c}\text { No. clones positive*/ } \\
\text { No. tested }\end{array}$ & $\begin{array}{c}{\left[{ }^{3} \mathrm{H}\right] \text { Thymidine }} \\
\text { uptake }\end{array}$ & $\begin{array}{c}\text { Stimulation } \\
\text { index }\end{array}$ \\
& & $\begin{array}{c}\text { mean } \text { cpm } \\
\times 10^{-3} \pm S D\end{array}$ & mean $\pm S D$ \\
Gp 30 & $13 / 39$ & $9.4 \pm 8.6$ & $23.5 \pm 15.0$ \\
Gp 42 & $11 / 22$ & $14.0 \pm 12.5$ & $42.0 \pm 33.1$ \\
L.d. chagasi lysate & $39 / 39$ & $32.9 \pm 17.2$ & $49.8 \pm 34.0$ \\
& & & \\
\hline
\end{tabular}

Response of $10^{4} \mathrm{~T}$ cells cultured with $10^{5}$ irradiated autologous PBL and $1 \mu \mathrm{g}$ protein of the indicated antigen, determined after $3 \mathrm{~d}$ of culture.

$* \geq 10$-fold stimulation index.

${ }^{\ddagger}$ Mean value of responding clones only.

crude leishmania extract. Many $\mathrm{T}$ cell clones generated from a patient with cured visceral leishmaniasis responded to both of these antigens, and $T$ cell lines generated against each of the antigens responded to both antigens. These findings, together with the observation that both antigens were among the most effective in stimulating PBL proliferation and IL-2 production suggests that these antigens may have one or more common epitopes. That they may have unique epitopes as well was indicated by the finding of several $\mathrm{T}$ cell clones, isolated after subcloning, which respond to one but not both of the antigens, and by the production of non-cross-reactive rabbit antisera. Gp 30 and gp 42 may be major antigens for $T$ cells, as indicated by the relatively high percentage of the clones analyzed that were specific for these antigens ( 13 of 39 tested and 11 of 22 tested, respectively). In addition, both gp 30 and gp 42 were effective in eliciting the production of IFN- $\gamma$ from $T$ cell lines from patients with either leishmaniasis or Chagas' disease. This may be an important consideration for selecting antigens as candidates for immunoprophylaxis because of the demonstrated importance of IFN- $\gamma$ in mediating intracellular destruction of leishmania (6). Additionally, it is of interest that all of the gp 30- and gp 42-specific $\mathrm{T}$ cell clones isolated were CD4+.

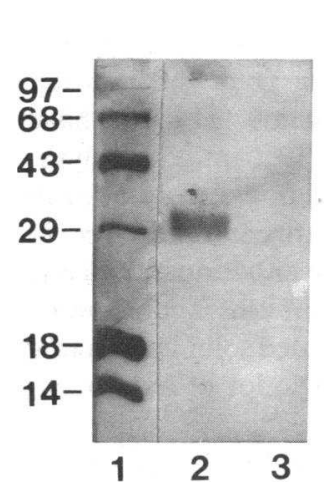

a

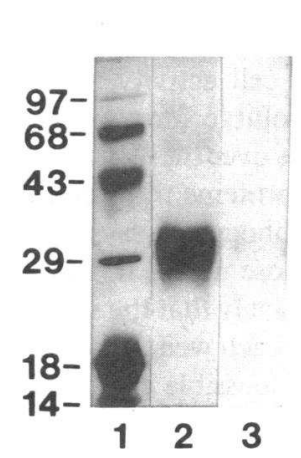

b

Figure 3. The 30-kD L. chagasi glycoprotein is susceptible to proteolytic treatment. $1 \mu \mathrm{g}$ protein of the eluted $30-\mathrm{kD}$ band ( $a$ and $b$, lane 2) was treated with $\mathrm{CNBr}(a$, lane 3$)$ or trypsin ( $b$, lane 3$)$ as described. $a$ and $b$, lane 1 , high molecular weight standards (Bethesda Research Laboratories). 
a

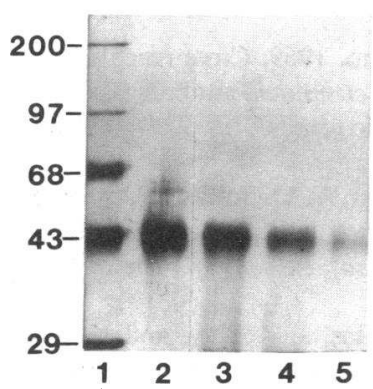

b

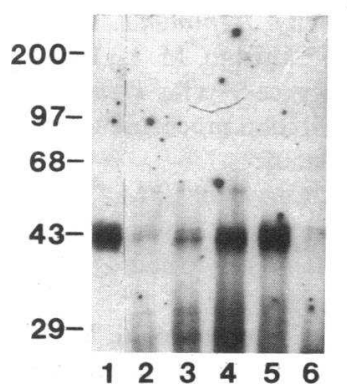

Figure 4. The $42-\mathrm{kD}$ glycoprotein is susceptible to proteolytic treatment. $a, 1 \mu \mathrm{g}$ protein of the eluted $42-\mathrm{kD}$ band (lane 2) was incubated with $\mathrm{CNBr}$ ( 2 parts $\mathrm{CNBr}: 1$ part protein) for $2.5 \mathrm{~h}$ (lane 3), $6 \mathrm{~h}$ (lane 4), or $16 \mathrm{~h}$ (lane 5). Lane 1, high molecular weight standards (Bethesda Research Laboratories). $b, 1 \mu \mathrm{g}$ protein of the eluted $42-\mathrm{kD}$ band (lane 1 ) was incubated with endolys $C$ at 400 parts protein: 1 part enzyme wt/wt (lane 2), 800 parts protein: 1 part enzyme (lane 3), and 3,200 parts protein: 1 part enzyme (lane 4 ) for $16 \mathrm{~h}$. In lane $5,1 \mu \mathrm{g}$ of the eluted $42-\mathrm{kD}$ band was incubated with trypsin, 100 parts protein: 1 part enzyme, wt/wt (lane 5), or 25 parts protein: 1 part enzyme (lane 6 ) for $16 \mathrm{~h}$.

The finding of leishmania antigens that stimulate proliferation and cytokine production by lymphocytes from Chagas' disease patients may be of particular significance. Experimentally, mice have been immunized against acute $T$. cruzi infection by prior inoculation of $L$. braziliensis (19) or $L$. chagasi (Reed, S. G., unpublished results). These observations, together with the in vitro findings in this report, suggest the potential of using leishmania antigens to immunize against $T$. cruzi. The finding that leishmania antigens induced IFN- $\gamma$ production by Chagas' patient $\mathrm{T}$ cells is relevant with regard to

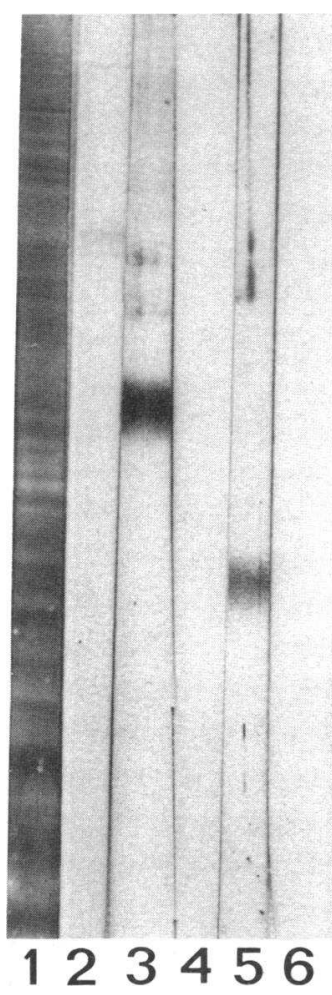

Figure 5. Treatment of eluted $L$. chagasi bands with lectin. Lanes 1 and 2 , whole $L$. chagasi lysate; lanes 3 and 4, 42-kD eluted protein; lanes 5 and 6, 30-kD eluted protein. Proteins were transferred to nitrocellulose and treated with biotinylated Lens culinaris (lanes 1,3 , and 5) followed by alkaline phosphatase avidin, or with alkaline phosphatase avidin only (lanes 2,4 , and 6 ), before addition of substrate.

a
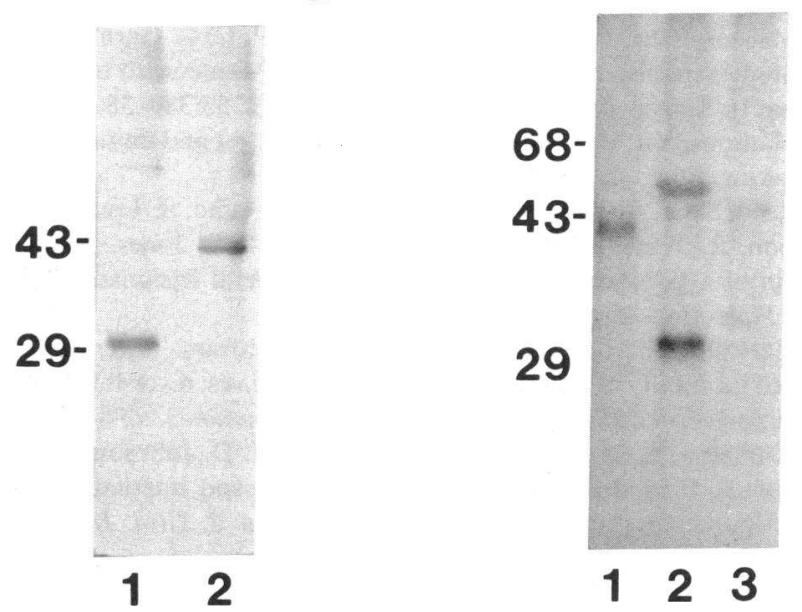

Figure 6. a, Immunoblot of $L$. chagasi lysate using rabbit antisera produced against the $30-\mathrm{kD}$ (lane 1 ) and the $42-\mathrm{kD}$ (lane 2) antigens. $5 \mu \mathrm{g}$ lysate protein/lane. $b$, Radioimmunoprecipitation of $L$. chagasi lysate using the same sera (lanes 1 [42 kD] and 2 [30 kD]) and normal rabbit serum (lane 3).

mechanisms of immune protection against acute $T$. cruzi infection. It has been shown that IFN- $\gamma$ can mediate resistance in experimental T. cruzi infections (20). Finally, because of the possibility that certain pathological manifestations of Chagas' disease are due to autoimmune responses induced by $T$. cruz $i$ antigens (reviewed in reference 21 ), the potential of immunizing against this infection with antigens other than those of $T$. cruzi may be of particular interest.

The possibility that the leishmania antigen-induced proliferation and cytokine production of PBL and T cell lines from Chagas' disease patients was due to multiple infections and not cross-reactivity is extremely slight. All of the Chagas' patients tested were from areas that are not endemic for leishmaniasis, and none had clinical histories, signs, or symptoms of any form of leishmaniasis. We have shown how the possibility of dual infection may be ruled out in a previous report (3).

In conclusion, we have begun to analyze antigens of leishmania that stimulate $T$ lymphocyte responses in patients with treated leishmaniasis. The emphasis in this study was to characterize antigens that are capable of stimulating $T$ cell responses from patients with infections caused by related parasites with the goal of identifying molecules having the potential to induce protective immune responses against more than one organism.

\section{Acknowledgments}

We thank Robert Jones for technical assistance and Karen Kinch for manuscript preparation. We are especially grateful to Drs. G. Grimaldi (Funadacao Oswaldo Cruz, Rio de Janeiro), R. Kopp (Van Nuys, CA), M. Peralta (Universidade Federal do Rio de Janeiro), D. Tabak (Instituto Nacional do Cancer, Rio de Janeiro), and S. Uman, Los Angeles, $\mathrm{CA}$, for their invaluable assistance in patient cell collection.

This work was supported by grants AI-25038 and AI-16282 from the National Institutes of Health and by the UNDP/World Bank/ World Health Organization special program for research and training in tropical diseases. Support was also received from the Murdock Trust. 


\section{References}

1. Manson-Bahr, P. E. C., R. B. Heisch, and P. C. C. Garnham. 1959. Studies in leishmaniasis in East Africa: the Montenegro test in Kala-azar in Kenya. Trans. R. Soc. Trop. Med. Hyg. 53:380-382.

2. Manson-Bahr, P. E. C. 1961. The leishmania test and immunity in Kala-azar. East Afr. Med. J. 38:165-166.

3. Reed, S. G., R. Badaro, H. Masur, E. M. Carvalho, R. Lorenco, A. Lisbon, R. Teixeira, W. D. Johnson, Jr., and T. C. Jones. 1986. Selection of a skin test antigen for American visceral leishmaniasis. Am. J. Trop. Med. Hyg. 35:79-85.

4. Carvalho, E. M., R. Teixeira, and W. D. Johnson. 1981. Cellmediated immunity in American visceral leishmaniasis: reversible immunosuppression during acute infection. Infect. Immun. 33:498-501.

5. Carvalho, E. M., R. Badaro, S. G. Reed, W. D. Johnson, and T. C. Jones. 1985. Absence of gamma interferon and interleukin 2 production during active visceral leishmaniasis. J. Clin. Invest. 76:2066-2069.

6. Murray, H. W., B. Y. Rubin, and C. D. Rothermel. 1983. Killing of intracellular Leishmania donovani by lymphokine-stimulated human mononuclear phagocytes. Evidence that interferon- $\gamma$ is the activating lymphokine. J. Clin. Invest. 72:1506-1510.

7. Reed, S. G., R. Badaro, and R. M. Cheri-Lloyd. 1987. Identification of specific and cross-reacting antigens of Leishmania donovani chagasi recognized by human infection sera. J. Immunol: 138:15961601.

8. Taswell, C. 1979. Limiting dilution assays for the determination of immune competent cell frequencies. I. Data analysis. J. Immunol. 126:1614-1618.

9. Lefkovits, I., and H. Waldmann. 1979. Limiting Dilution Analysis of Cells in the Immune System. Cambridge University Press, London.

10. Stewart, W. D. 1981. The Interferon System. Springer-Verlag, New York Inc., New York. 13-24.

11. Gillis, S., M. M. Ferm, W. Ou, and X. A. Smith. 1978. T cell growth factor: parameters of production and a quantitative microassay for activity. J. Immunol. 120:2027-2032.

12. Camargo, M. E., and C. Rebonato. 1969. Cross reactivity in fluorescence tests for Trypanosoma and Leishmania antibodies: a simple inhibition procedure to ensure specific results. Am. J. Trop. Med. 18:500-505.

13. Carvalho, E. M., S. G. Reed, and W. D. Johnson, Jr. 1987. Cross-reactivity between Trypanosoma cruzi and Leishmania antigens in the lymphocyte blastogenisis assay. Trans. R. Soc. Trop. Med. Hyg. 81:82-84.

14. Colomer-Gould, V., L. G. Quintas, J. Keithly, and N. Nogueira. 1985. A common major surface antigen on amastigotes and promastigotes of Leishmania species. J. Exp. Med. 162:902-907.

15. Lapay, D. A., N. Nogueira, and Z. A. Cohn. 1983. Surface antigens of Leishmania donovani promastigotes. J. Exp. Med. 157:156-162.

16. Russel, D. G., and J. Alexander. 1988. Effective immunization against cutaneous leishmaniasis with defined membrane antigens reconstituted into liposomes. J. Immunol. 140:1274-1277.

17. Hurwitz, J. L., E. Heber-Katz, C. J. Hackett, and W. Gerhard. 1984. Characterization of the murine Th response to influenza virus hemaglutinin: evidence for three major specificities. J. Immunol. 133:3371-3376.

18. Lamb, J. R., D. D. Eckels, P. Lake, J. N. Wood, and N. Green. 1982. Human $T$ cell clones recognize chemically synthesized peptides of influenza haemagglutinin. Nature (Lond.). 300:66-68.

19. Tanowitz, H. B., B. Amole, R. Herman, and M. Wittner. 1986. Protection against fatal murine Chagas' disease with a Leishmania braziliensis panamensis stock. Am. J. Trop. Med. Hyg. 35:937-941.

20. Reed, S. G. 1988. In vivo administration of recombinant interferon-gamma induces macrophage activation, and prevents acute disease, immune suppression, and death in experimental Trypanosoma cruzi infection. J. Immunol. 140:4342-4347.

21. Santos-Buch, C. A. 1979. American trypanosomiasis: Chagas' disease. Int. Rev. Exp. Pathol. 19:63-100. 